\title{
Serum homocysteine and folate levels as a predictor of materno-fetal outcome in preeclamptic women
}

\author{
Namita Jain ${ }^{1 *}$, Abha Singh ${ }^{2}$, Jayashree Bhattacharjee ${ }^{3}$
}

\begin{abstract}
${ }^{1}$ Department of Obstetrics and Gynecology, Mahatma Gandhi Medical College, Jaipur, Rajasthan, India
${ }^{2}$ Department of Obstetrics and Gynecology, ${ }^{3}$ Department of Biochemistry, Lady Hardinge Medical College, Delhi, India
\end{abstract}

Received: 18 September 2018

Accepted: 22 October 2018

\author{
*Correspondence: \\ Dr. Namita Jain, \\ E-mail: namita.hardonian@gmail.com
}

Copyright: (c) the author(s), publisher and licensee Medip Academy. This is an open-access article distributed under the terms of the Creative Commons Attribution Non-Commercial License, which permits unrestricted non-commercial use, distribution, and reproduction in any medium, provided the original work is properly cited.

\begin{abstract}
Background: To study the role of serum homocysteine and serum folate levels in prediction of materno-fetal outcome in preeclamptic women, especially in early onset preeclampsia.

Methods: This prospective study was conducted in a tertiary care teaching hospital in India. 60 preeclamptic women (Group A) that were matched with 60 normotensive pregnant women (Group B), with singleton pregnancy and gestational age between 24-32 weeks attending antenatal clinics were included in the study. Maternal blood was collected twice first at time of enrolment and second at delivery. Serum homocysteine and serum folate levels were analyzed using enzymatic assay and chemiluminescent immunoassay. Mean rise in serum homocysteine and folate levels were calculated individually in all patients.

Results: Mean homocysteine levels were significantly higher in Group A as compared to Group B both at enrolment and delivery $(\mathrm{p}<0.05)$. Women with higher rise in mean homocysteine levels were associated with an increased risk of adverse maternal complications ( $p$ <05). Mean rise in homocysteine levels were significantly higher in women who developed abruption and perinatal death $(\mathrm{p}<0.05)$ while no correlation was found with the mean change in serum folate levels $(\mathrm{p}>0.05)$.

Conclusions: Serum homocysteine can be used as a reliable marker for predicting the severity of preeclampsia and adverse pregnancy (both maternal and fetal) outcome thus helps in reducing maternal and fetal morbidity and mortality, especially in women with early onset preeclampsia.
\end{abstract}

Keywords: Folate, Homocysteine, Maternal complications, Materno-fetal outcome, Preeclampsia

\section{INTRODUCTION}

Preeclampsia along with the other hypertensive disorders of pregnancy complicates $2-8 \%$ of pregnancies and is a major contributor to maternal and perinatal mortality worldwide1. Preeclampsia is defined as hypertension and proteinuria detected in the second half of pregnancy i.e. after 20 weeks gestation. Furthermore, complications depend on severity of preeclampsia leading to maternal morbidity and mortality and adverse perinatal outcome. ${ }^{1}$ The exact cause of preeclampsia remains unclear.
Placenta has been suggested as the pathogenic focus for all manifestations of preeclampsia. One of the most striking physiologic changes in preeclampsia is systemic vasospasm responsible for decreased perfusion of virtually all organs.

Homocysteine is a sulfur-containing, nonproteinogenic amino acid biosynthesized from methionine and which has three main metabolic fates: to be remethylated to methionine, to enter the cysteine biosynthetic pathway, or to be released into the extracellular medium observed as 
increased concentrations of total homocysteine in extracellular fluids like plasma and urine. ${ }^{2}$

Endothelial cell damage due to oxidative stress caused by homocysteine has also been considered as a mechanism in the pathophysiology of preeclampsia. An alternative hypothesis suggests that homocysteine is acting indirectly through its oxidation and the concomitant production of reactive oxygen species. ${ }^{3}$

Folate deficiency is associated with raised homocysteine, which is associated with increased risk of vascular disease. $^{4}$ There is no evidence that lowering homocysteine by increased intake of folate results in diminution of risk of vascular disease. Considerable genetic heterogeneity exists with respect to homocysteine metabolism because of methylene tetrahydrofolate reductase (MTHFR) polymorphisms. ${ }^{5}$ Therefore, folate requirements may, vary considerably between individuals and different levels of intake may be required to control hyperhomocysteinemia and modify its potential effects.

Early prediction of preeclampsia requires close surveillance and preventive strategies. Numerous studies have evaluated tests to predict preeclampsia. No single test is likely to be effective in prediction of the onset of a heterogeneous disorder preeclampsia. Researchers have suggested that combination of tests along with the serum markers may raise the effectiveness of preeclampsia screening.

Therefore, in the present study, serum homocysteine and serum folate levels were measured and correlated with materno-fetal outcome in women with preeclampsia.

\section{METHODS}

This prospective study was conducted in Department of Obstetrics and Gynecology, Lady Hardinge Medical College and Smt. Sucheta Kriplani Hospital, New Delhi, India, from October 2013 to March 2014. This study protocol was approved by the institutional ethics committee. 120 women were recruited in the study and divided into two groups. Group A included 60 women with preeclampsia $(n=60)$ and Group B included 60 normotensive pregnant women $(n=60)$. Women with resting blood pressure of $\geq 140 / 90 \mathrm{mmHg}$ on two occasions at least $6 \mathrm{hrs}$ apart and significant proteinuria in urine samples were included in the study group after an informed consent. All subjects were singleton pregnancy and with gestational age between 24-32weeks. Women with diagnosis of chronic hypertension, twin/ multifetal gestation, neural tube defect, diabetes mellitus, repeated miscarriages, abruptio placenta, history of smoking, preexisting renal disease, liver disease or prior significant medical illness, history of thromboembolism and severe anemia $(<7 \mathrm{gm} \%)$ were excluded from the study. Participants were subjected to history and detailed examination. None of the subjects were in labor (latent or active) or had any signs of infection. All subjects were taking folic acid supplementation throughout the course of pregnancy. Maternal venous blood sample $(5 \mathrm{ml})$ was collected at any time of the day in a sterile vial and kept at room temperature for $30 \mathrm{~min}$ and then centrifuged at $3000 \mathrm{rpm}$ for 10 minutes. Precaution was taken to prevent the deterioration of the samples from light. Within two hours after centrifugation, $500 \mu \mathrm{L}$ of cell-free sample was transferred to a storage tube. The serum aliquots were frozen at $-20 \circ \mathrm{C}$ till the time of analysis. After separation of serum from cells, homocysteine is stable for at least 4 days at room temperature, stable for several weeks at 0 $8 \circ \mathrm{C}$ and stable for several months or years at $-20^{\circ} \mathrm{C}$. Samples were thawed only once. Sample for homocysteine and folate were taken twice, first at enrolment and second at delivery.

\section{Measurement of serum homocysteine levels}

The serum homocysteine levels were measured by enzymatic assay by using SYNCHRON CX9 PRO system. The absorbance of each tube was determined at $340 \mathrm{~nm}$. The machine was calibrated using the standard given along with the kit and Quality control was run each time before analyzing the patient sample. The results were obtained in $\mu \mathrm{mol} / 1$.

\section{Measurement of serum folate levels}

The serum folate levels were measured by chemiluminescent immunoassay. The absorbance of each tube was determined in ACCESS2 machine. The machine was calibrated using the standard given along with the kit and each time Quality control (Qc) was run before analyzing the patient sample. The results were obtained in $\mathrm{ng} / \mathrm{ml}$.

\section{Statistical analysis}

It was done using statistical package for social sciences version 18 (SPSS 18.0). All values were expressed as mean and standard deviations. Independent t-test was performed for comparing mean of the groups. Moreover, correlation analysis was performed using Pearson's product moment correlation coefficient. For the purpose of this study $95 \%$ confidence interval was chosen and corresponding $\mathrm{p}$ value $<0.05$ was taken as statistically significant.

\section{RESULTS}

The maternal demographic characteristics were similar between the groups. The mean age of the women recruited in the study group (Group A) was 24.43 \pm 3.80 years and 23.62 \pm 2.65 years in control group (Group B). Women in both groups were enrolled at the mean gestation $30.06 \pm 1.33$ and $29.96 \pm 1.07$ weeks.

In Group A, $58 \%$ of the cases were delivered before 32 weeks of gestation, 35\% at gestation of 32.1-36 weeks and only $7 \%$ of the cases reached term while, in Group B 
$92 \%$ of the cases were delivered at term. Mean DBP on admission in Group A was $99.43 \pm 7.85$ and in Group B was $67.26 \pm 6.85 \mathrm{mmHg}$. Mean $24 \mathrm{hr}$ proteinuria in Group A was $1.47 \pm 0.68 \mathrm{gm} / \mathrm{L}$ and was $0.17 \pm 0.79 \mathrm{gm} / \mathrm{L}$ in Group B. Mean uric acid was $6.24 \pm 1.39 \mathrm{mg} / \mathrm{dl}$ in Group A and $3.10 \pm 0.66 \mathrm{mg} / \mathrm{dl}$ in Group B (p value-0.00) and similarly, triglyceride was $278.20 \pm 97.85 \mathrm{mg} / \mathrm{dl}$ and $198.57 \pm 49.62$ $\mathrm{mg} / \mathrm{dl}$ in Group A and Group B respectively ( $\mathrm{p}$ value0.000). Mean homocysteine levels were higher in Group A as compared to Group B both at enrolment (9.41 \pm 2.99 vs $7.25 \pm 2.43 \mu \mathrm{mol} / \mathrm{L})$ and delivery $(16.32 \pm 5.30$ vs $9.56 \pm 2.98 \mu \mathrm{mol} / \mathrm{L})$ and statistically significant mean rise in homocysteine levels in both the groups from enrolment to delivery. Insignificant difference was seen in serum folate levels in both the groups from enrolment till delivery (Table 1).
There was insignificant negative correlation between homocysteine and folate levels at enrolment and at delivery in Group A $\{\mathrm{r}=(-) .172$ and (-).079 at enrolment and delivery respectively\}. There was a weakly positive correlation between homocysteine and folate levels and was found to be statistically significant at enrolment and insignificant at delivery $\{\mathrm{r}=(+) .25$ and $(+) .065$ at enrolment and delivery respectively $\} .43 \%$ of the women developed severe hypertension, $8 \%$ had deranged liver and renal function tests, $15 \%$ had thrombocytopenia while $19 \%$ developed eclampsia. Women developing complications like severe hypertension, deranged liver and renal function tests, thrombocytopenia and eclampsia had a higher mean rise in serum homocysteine levels that was statistically significant (Table 2).

Table 1: Homocysteine and folate levels in study groups.

\begin{tabular}{|c|c|c|c|c|c|c|}
\hline & \multicolumn{3}{|l|}{ Group A } & \multicolumn{3}{|l|}{ Group B } \\
\hline & Enrolment & Delivery & $p$ value & Enrolment & Delivery & p value \\
\hline Serum homocysteine $(\mu \mathrm{mol} / \mathrm{L})$ & $9.41 \pm 2.99$ & $16.32 \pm 5.30$ & 0.00 & $7.25 \pm 2.43$ & $9.56 \pm 2.98$ & 0.00 \\
\hline Serum Folate $(\mathrm{ng} / \mathrm{dl})$ & $9.33 \pm 6.28$ & $10.63 \pm 6.11$ & 0.12 & $9.63 \pm 4.78$ & $10.31 \pm 4.93$ & 0.22 \\
\hline
\end{tabular}

Table 2: Maternal complications with mean rise in homocysteine level.

\begin{tabular}{|c|c|c|c|c|c|c|}
\hline \multirow{2}{*}{ Maternal complications } & & \multirow{2}{*}{$\begin{array}{l}\text { Group A No. }(\%) \\
(n=60)\end{array}$} & \multicolumn{3}{|c|}{ Homocysteine levels $(\mu \mathrm{mol} / \mathrm{l})$} & \multirow{2}{*}{ p value } \\
\hline & & & Mean Rise & SD & Range & \\
\hline \multirow{2}{*}{$\begin{array}{l}\text { Severe hypertension } \\
(\mathrm{BP} \geq 160 / 110)\end{array}$} & Present & $26(43)$ & 8.61 & 2.23 & $0.15-11.91$ & \multirow{2}{*}{0.00} \\
\hline & Absent & $34(57)$ & 6.05 & 2.46 & $1.66-10.00$ & \\
\hline \multirow{2}{*}{$\begin{array}{l}\text { Deranged renal function } \\
(\text { S.cr. }>1.2 \mathrm{mg} / \mathrm{dl})\end{array}$} & Present & $05(08)$ & 9.68 & 1.47 & $7.89-11.91$ & \multirow{2}{*}{0.01} \\
\hline & Absent & $55(92)$ & 6.93 & 2.64 & $0.15-11.57$ & \\
\hline \multirow{2}{*}{$\begin{array}{l}\text { Deranged liver enzyme } \\
(\mathrm{AST}>40 \mathrm{u} / \mathrm{ml})\end{array}$} & Present & $05(08)$ & 9.30 & 0.64 & $8.75-10$ & \multirow{2}{*}{0.03} \\
\hline & Absent & $55(92)$ & 6.97 & 2.70 & $0.15-11.91$ & \\
\hline \multirow{2}{*}{$\begin{array}{l}\text { Thrombocytopenia } \\
(<1.01 \mathrm{lac})\end{array}$} & Present & $09(15)$ & 8.53 & 2.19 & $3.17-11.91$ & \multirow{2}{*}{0.04} \\
\hline & Absent & $51(85)$ & 6.9 & 2.69 & $0.15-11.57$ & \\
\hline \multirow{2}{*}{ Eclampsia } & Present & $11(19)$ & 8.86 & 1.38 & $6.54-11.91$ & \multirow{2}{*}{0.009} \\
\hline & Absent & $49(81)$ & 6.78 & 2.76 & $0.15-11.57$ & \\
\hline
\end{tabular}

Out of 60 women in Group A, labor was induced/ augmented in $92 \%$ of the women. Most of the women were induced in view of abnormal Doppler studies, intrauterine deaths and abruption.

$27 \%$ of the women underwent caesarean section in view of abnormal Doppler waveforms and uteroplacental insufficiency. $5 \%$ of the women had term low birth weight babies (LBW), 44\% had perinatal death $(35 \%$ intrauterine and $8 \%$ neonatal deaths) and rest of the women delivered preterm live baby.

While in group B $10 \%$ of the women had LBW babies. $10 \%$ delivered by caesarean and rest had normal vaginal delivery. Maternal mortality was not observed in any of the women in both the groups. Women with abruption, intrauterine and neonatal death had significant mean rise in homocysteine levels (Table 3).

No definite correlation was seen between mean changes in serum folate with maternal outcome. Mean birth weight in Group A was 1174.08 $\pm 351.18 \mathrm{gms}$ and in Group B was 2736.66 $\pm 266.28 \mathrm{gms}$ (p value-0.01).

In Group A mean apgar score at $1 \mathrm{~min}$ and $5 \mathrm{~min}$ was $4.05 \pm 3.58$ and 5.21 \pm 3.99 while in Group B mean apgar at $1 \mathrm{~min}$ and $5 \mathrm{~min}$ was $7.58 \pm 1.23$ and $8.55 \pm 1.27$ (p value$0.00,0.05$ respectively).

As the mean homocysteine levels increased there was an increase in severity of LBW to extremely low birth weight (ELBW) babies. 
Table 3: Comparison of maternal outcome with rise in homocysteine.

\begin{tabular}{|c|c|c|c|c|c|c|c|}
\hline \multirow{2}{*}{$\begin{array}{l}\text { Maternal outcome } \\
\text { parameter }\end{array}$} & & & \multirow{2}{*}{$\begin{array}{l}\text { Group A No. (\%) } \\
(\mathrm{n}=60)\end{array}$} & \multicolumn{3}{|c|}{ Homocysteine levels umol/l } & \multirow[b]{2}{*}{ p value } \\
\hline & & & & Mean rise & SD & Range & \\
\hline \multirow[t]{2}{*}{ Abruption } & Present & & $11(19)$ & 8.00 & 2.36 & $3.7-10$ & \multirow{2}{*}{0.04} \\
\hline & Absent & & $49(81)$ & 6.50 & 2.72 & $0.15-11.91$ & \\
\hline \multirow{4}{*}{$\begin{array}{l}\text { Outcome of } \\
\text { pregnancy }\end{array}$} & Fullterm 1 & & $03(5)$ & 5.59 & 2.39 & $3.97-8.38$ & \multirow{4}{*}{0.00} \\
\hline & Preterm li & & $31(52)$ & 5.63 & 2.38 & $0.15-10.00$ & \\
\hline & \multirow{2}{*}{$\begin{array}{l}\text { Perinatal } \\
\text { death }\end{array}$} & IUD & $21(35)$ & 9.07 & 1.20 & $6.32-11.91$ & \\
\hline & & NND & $05(8)$ & 9.74 & 1.33 & $7.89-11.57$ & \\
\hline
\end{tabular}

Table 4: Comparison of fetal outcome with rise in homocysteine.

\begin{tabular}{|c|c|c|c|c|c|c|}
\hline \multirow{2}{*}{$\begin{array}{l}\text { Fetal outcome } \\
\text { parameters }\end{array}$} & & \multirow{2}{*}{$\begin{array}{l}\text { Group A No. (\%) } \\
(\mathrm{n}=60)\end{array}$} & \multicolumn{3}{|c|}{ Homocysteine Levels $\mu \mathrm{mol} / \mathrm{l}$} & \multirow{2}{*}{ p value } \\
\hline & & & Mean rise & SD & Range & \\
\hline \multirow{3}{*}{ Birth weight } & ELBW $(<1 \mathrm{~kg})$ & $20(33)$ & 8.61 & 1.79 & $3.37-10$ & \multirow{3}{*}{0.007} \\
\hline & VLBW (1-1.49kg) & $32(54)$ & 6.83 & 2.80 & $0.15-11.91$ & \\
\hline & LBW $(1.5-2.49 \mathrm{~kg})$ & $08(13)$ & 6.22 & 2.73 & $1.66-9.65$ & \\
\hline \multirow{2}{*}{ Apgar at 1 minute } & $<7$ & $13(33)^{*}$ & 6.38 & 2.73 & $1.66-10$ & \multirow{2}{*}{0.40} \\
\hline & $>7$ & $26(67)$ & 6.15 & 2.72 & $0.15-11.57$ & \\
\hline \multirow{2}{*}{ Apgar at 5 minute } & $<7$ & $04(10)^{*}$ & 7.14 & 2.12 & 4.6-10 & \multirow{2}{*}{0.23} \\
\hline & $>7$ & $35(90)$ & 6.09 & 2.77 & $0.15-11.57$ & \\
\hline \multirow{3}{*}{$\begin{array}{l}\text { Perinatal } \\
\text { death }\end{array}$} & IUD & $21(35)$ & 9.07 & 1.20 & $6.32-11.91$ & \multirow{3}{*}{0.002} \\
\hline & NND & $05(08)$ & 9.74 & 1.33 & 7.89-11.57 & \\
\hline & No & $34(57)$ & 5.37 & 2.29 & $0.15-10.00$ & \\
\hline
\end{tabular}

*21 IUD's were excluded

Significant negative correlation was observed between mean rise in homocysteine with birth weight and intrauterine death (IUD) while insignificant negative relation was seen in babies with low Apgar score. This shows that women with low birth weight, intrauterine and neonatal deaths had higher mean rise in homocysteine levels, which is statistically significant (Table 4). No definite correlation was seen between mean changes in folate levels with fetal outcome.

\section{DISCUSSION}

The mean gestation of enrolment in the present study was $30.06 \pm 1.33$ weeks and $29.96 \pm 1.07$ weeks in Group A and Group B respectively which is comparable to the $\mathrm{Md}$. Hoque et al study. ${ }^{6}$ In study by Cotter et al, disparity was seen in the mean gestation at enrolment, as samples were taken prior to the onset of preeclampsia. ${ }^{7}$

The mean gestation at delivery in the present study was comparable to Acilmis et al and Powers at al. ${ }^{8,9}$ The gestation at delivery varies according to the severity and complications of preeclampsia. It has been seen in the literature that women with onset of preeclampsia prior to 34 weeks is severe in nature and aggressive management is required in many of them either due to uteroplacental insufficiency or complications of preeclampsia.

In the present study, mean uric acid was $6.24 \pm 1.39 \mathrm{mg} / \mathrm{dl}$ in Group A and 3.10 $\pm 0.66 \mu \mathrm{g} / \mathrm{dl}$ in Group B and similarly, triglyceride was $278.20 \pm 97.85 \mathrm{mg} / \mathrm{dl}$ and $198.57 \pm 49.62 \mathrm{mg} / \mathrm{dl}$ in Group A and B respectively. Results in the present study were in accordance with the previous studies. In present study, mean homocysteine level at enrolment in both the groups was comparable to studies conducted by Powers et al, Cotter et al, and Hoque et al. Mean homocysteine levels were higher in studies by Ingec et al and by Singh et al..$^{6,7-11}$ High levels can be attributed to the severity of preeclampsia in the study group. In study by Singh et al, baseline homocysteine levels were higher in all the three groups. In Ingec et al study, samples were collected in the fasting state and homocysteine measurement was done using high performance liquid chromatography (HPLC) in Ingec et al study and by fluorescence polarization immunoassay (FPIA) in study by Singh et al. Both HPLC and FPIA are more sensitive methods for measurement of homocysteine as compared to enzymatic immunoassay (EIA) used in the present study.

Mean rise in homocysteine was significantly higher in both the groups. In normal pregnancy, homocysteine concentration tends to fall due to many factors like hemodilution, increased GFR, hormonal changes and increased uptake by the fetus. Maximum fall is seen in second trimester and levels rise again by the end of third trimester to regain the values of first trimester. ${ }^{12}$ The higher mean rise in homocysteine in women with preeclampsia may indicate the progression to more severe form of the disease. 
Mean rise in homocysteine levels in women with preeclampsia with advancing gestation have not been well documented and more studies are required for the role of serial estimation of homocysteine in preeclamptic women. Thus, hyperhomocysteinemia is associated with increasing severity of preeclampsia.

Mean serum folate levels in present study were comparable to results obtained by Acilmis et al. ${ }^{8}$ In present study, no significant difference was found in Group A and B at time of enrolment and delivery and insignificant change was noticed in levels of folate in both the groups from enrolment till delivery. Folate levels at enrolment were lower in severe preeclamptic group as compared to mild preeclampsia and Group B. This finding of insignificant difference in folate was supported by studies like study by Mignini et al, Powers et al and Acilmis et al. ${ }^{8,9,12}$ All the women recruited in the study were continued on folic acid supplements. It has been reported that dietary requirement of folate is increased for regulating $\mathrm{HC}$ in women carrying thermolabile variant of MTHFR gene as reduced serum folate levels has been observed in pregnant women with this gene. ${ }^{5}$ Insignificant difference in serum folate in present study suggested that no folic acid deficiency was detected in this small group of women.

In the present study, serum samples for both homocysteine and folate were taken twice, first at time of enrolment (24-32 weeks) and second before delivery. Hogg et al13 suggested that if levels of HC were measured in early gestation, they might have found elevated plasma HC concentration both in early pregnancy and at time of delivery in cases with early onset severe disease. Leeda et al, gave folic acid and Vit B6 supplementation to 14 patients with a previous history of hyperhomocysteinemia and severe preeclampsia/ HELLP syndrome in previous pregnancy and found that although half patients developed preeclampsia, but the outcome was much better. This suggests that hyperhomocysteinemia can be due to genetic or nutritional defect or both. ${ }^{14}$ So, further investigations are required for ascertaining the factors responsible for HHCh. Study by Hoque et al and Ingec et al have reported higher plasma levels of homocysteine in women with eclampsia than women with mild preeclampsia group and control subjects. Similar results were obtained in the present study. ${ }^{6,10}$

Mean rise in homocysteine was significantly higher in women who developed maternal complications. This signifies that hyperhomocysteinemia has positive correlation with maternal complications. In study by Makedos et al on 26 cases, delivery by caesarean was seen in $75 \%$, abruption in $7 \%$ and intrauterine deaths in $7 \%$ of the cases. ${ }^{15}$ While in present study, delivery by caesarean occurred in $27 \%$, abruption in $19 \%$ and intrauterine deaths in $35 \%$. Mean age of enrolment was $34 \pm 6.0$ weeks in study by Makedos et al while in present study it was $30.06 \pm 1.33$ weeks. ${ }^{15}$ In view of prematurity women were kept on conservative management till the maternal complications or uteroplacental insufficiency developed. In the present study, mean rise in homocysteine level was significantly higher in women who had abruption, intrauterine or neonatal death. Mean rise in homocysteine levels correlated with poor maternal outcome while no correlation was found between mean change in folate levels and maternal outcome.

In present study, $33 \%$ of women gave birth to extremely low birth weight babies, $54 \%$ had very low birth weight babies and $13 \%$ had low birth weight babies. $35 \%$ of the women had intrauterine deaths while $8 \%$ had neonatal death. Mean gestational age at enrolment in women with preeclampsia in present study was 30.06 weeks. In Group A mean birth weight in present study was $1174.08 \pm 351.18 \mathrm{gms}$. Mean birth weight in Group B was comparable to birth weight in the studies mentioned in the table. $10 \%$ of low birth weight babies were seen in Group B. Low birth weight babies were also observed in studies by Powers et al and Makedos et al. ${ }^{9,15}$ This is due to the fact that preeclampsia of early onset ( $<34$ weeks) is generally severe in nature and is associated with an inadequate and incomplete trophoblast invasion of maternal spiral arteries which leads to uteroplacental insufficiency, resulting in fetal growth restriction.

Mean homocysteine rise was found to be significantly higher in women with poor fetal outcome like low birth weight and perinatal death (intrauterine and neonatal death). Mean rise in homocysteine had a significant negative correlation with the birth weight in the present study. In the present study, there was no association between the change in the mean levels of folate and fetal outcome. Thus, present study demonstrates that mean homocysteine levels in women with early onset preeclampsia is significantly higher than the normotensive pregnant women. Significant difference in the homocysteine levels is seen from enrolment to delivery while insignificant difference was seen in the serum folate levels in both the groups. Pregnant women who developed complications had shown a significant rise in mean homocysteine levels. Pregnancies with poor maternal and fetal outcome were found to have no correlation with mean change in serum folate levels however, significant correlation was observed with rise in mean homocysteine levels.

\section{CONCLUSION}

Serum homocysteine can be used as a reliable marker for predicting the severity of preeclampsia and adverse pregnancy (both maternal and fetal) outcome, thus helps in reducing maternal and fetal morbidity and mortality, especially in women with early onset preeclampsia.

Funding: No funding sources

Conflict of interest: None declared

Ethical approval: The study was approved by the Institutional Ethics Committee 


\section{REFERENCES}

1. Duley L. The global impact of pre-eclampsia and eclampsia. InSeminars in perinatology. WB Saunders.2009 33(3):130-7.

2. Medina MÁ, Urdiales JL, Amores-Sánchez MI. Roles of homocysteine in cell metabolism: old and new functions. Europe $\mathrm{J}$ Biochem. 2001;268(14):3871-82.

3. Jacobsen, DW. Homocysteine and vitamins in cardiovascular disease. Clin Chem 1998; 44(8):183343

4. Miller JW. Does lowering plasma homocysteine reduce vascular disease risk? Nutr Rev 2001; 59(7):242-4

5. Molloy AM, Daly S, Mills JL, Kirke PN, Whitehead AS, Ramsbottom D et al. Thermolabile variant of 5, 10-methylenetetrahydrofolate reductaseassociated with low red-cell folates: implications for folate intake recommendations. The Lancet. 1997;349(9065):1591-3.

6. Hoque MM, Bulbul T, Mahal M, Islam NA, Ferdausi M. Serum homocysteine in pre-eclampsia and eclampsia. Bangladesh Med Res Coun Bullet. 2008;34(1):16-20.

7. Cotter AM, Molloy AM, Scott JM, Daly SF. Elevated plasma homocysteine levels in early pregnancy: A risk factor for the development of severe preeclampsia. Am J Obstet Gynecol 2001;185(4):781-85.

8. Acılmis YG, Dikensoy E, Kutlar AI, Balat O, Cebesoy FB, Ozturk E et al. Homocysteine, folic acid and vitamin B12 levels in maternal and umbilical cord plasma and homocysteine levels in placenta in pregnant women with pre-eclampsia. J Obstet Gynaecol Res 2011;37(1):45-50

9. Powers R, Evans R, Majors A, Ojimba J, Ness R, Gromble-holme W. Plasma homocysteine concentration is increased in preeclampsia and is associated with evidence of endothelial activation. Am J Obstet Gynecol 1998; 179(6):1605-11

10. Ingec M, Borecki B, Kadanali S. Elevated plasma homocysteine concentrations in severe preeclampsia and eclampsia. Tohuku J Exp Med 2005; 206(3):225-31

11. Singh U, Gupta HP, Singh RK, Shukla M, Mehrotra S, Prasad S. Homocysteine: association with preeclampsia and normotensive pregnancy. The Journal of Obstetrics and Gynecology of India 2009;59:235-8

12. Mignini, Luciano E. Latthe, Pallavi M, Villar, Jose, Kilby, Mark D, Carroli, Guillermo, Khan, Khalid. Mapping the Theories of Preeclampsia: The Role of Homocysteine. Obstet Gynecol 2005;105(2):411-25

13. Hogg BB, Tamura T, Johnston KE, Mary B, Dubard, Goldenberg RL. Second trimester plasma homocysteine levels and pregnancy induced hypertension, preeclampsia and intrauterine growth restriction. Am J Obstet Gynecol 2000;183(4):80509

14. Leeda M, Riyazi N, Vries JI, Jakobs C, van Geijn HP, Dekker GA. Effects of folic acid and vitamin B6 supplementation on women with hyperhomocysteinemia and a history of preeclampsia or fetal growth restriction. Am J Obstet Gynecol. 1998;179(1):135-9

15. Makedos G, Papanicolaou A, Hitoglou A. Homocysteine, folic acid and B12 levels in pregnancy complicated with preeclampsia. Arch Gynecol Obstet 2007;275(2):121-4.

Cite this article as: Jain N, Singh A, Bhattacharjee J. Serum homocysteine and folate levels as a predictor of materno-fetal outcome in preeclamptic women. Int J Reprod Contracept Obstet Gynecol 2018;7:493944. 